\title{
Cortical deficit in early HIV infection
}

\author{
C Bungener ${ }^{1}$, R Jouvent ${ }^{1}$, F Raffi ${ }^{2}$, D Widlöcher ${ }^{1}$ \\ 'Groupe Cognem, INSERM 302, Paris; '2Service de Médecine Interne, CHR Nantes, France
}

Studies of the early symptomatology of HIV infection have shown cognitive and psychiatric disturbances (Dew, 1990). Among psychiatric manifestations a previous study has shown the presence of an important emotional deficit. This blunted effect or emotional deficit was already present in asymptomatic stages of the disease; and was significantly more important than in a population of paired controls (Bungener et al, 1991).

We hypothesise that this emotional deficit could be linked with early neurological impairment. Assuming that this impairment is related to cortical dysfunctioning, we used the critical flicker fusion frequency threshold (CFF). This test is defined as the fastest rate at which an intermittent light source still appears to be flickering as opposed to being steady; the frequency of the light flashes at which the flicker disappears is called critical fusion frequency (Bobon et al, 1982). It measures the cortical activation and can be considered as a physiological evaluation of CNS arousal.

The CFF has been assessed in a population of 17 HIV-positive homosexual men. All were asymptomatic according to the CDC criteria (stage II, III or IVc2). Mean age was $33.5 \pm 7.8$ (range: $22-54$ ). The mean duration of the known seropositivity was $28.8 \pm 22$ months (range: 6-84). Subjects were not depressed, mean score on the MADRS was $9.8 \pm 4.82$ (range: $3-22$ ) and were slightly anxious, mean score on the Covi anxiety scale was $5.88 \pm 3.2$ (range: $1-8$ ). However, they presented quite important scores of emotional deficit, mean score on the Abrams and Taylor scale for emotional blunting was $9.47 \pm 2$ (range: 8-14), and $7.1 \pm 2.7$ (range: $2-13$ ) on the blunted affect factor of the Depressive Mood scale.

The mean CFF threshold was $29.6 \pm 2.6$ (range: 23.6-33.7). Results showed a negative correlation $(r=-0.70)$ between the CFF and the duration of the known seropositivity. The age of the patients and the known seropositivity are not correlated. No other correlation has been found. This result is in favor of the presence of a cortical deficit in the

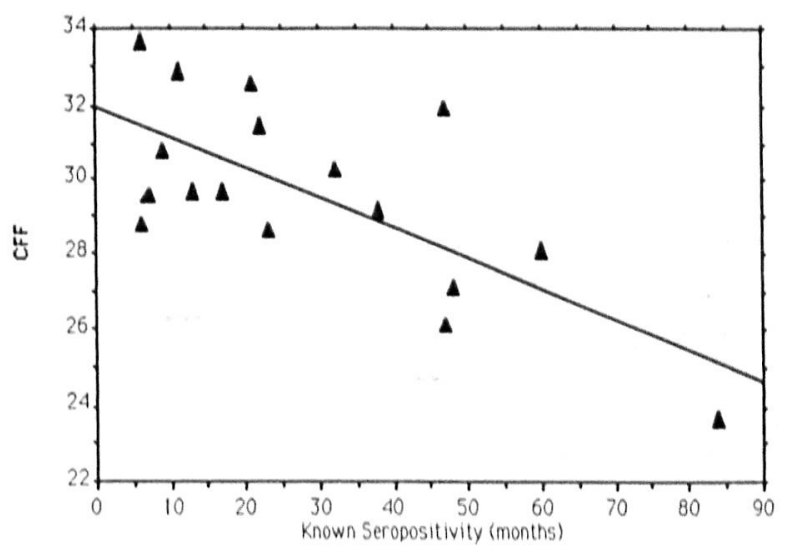

Fig 1. Correlation between CFF and known seropositivity. 
asymptomatic stages of HIV infection; however in the absence of a control group, this result remains difficult to analyse. In order to prove that the decrease in the activation level is linked to HIV infection, further studies with a control group need to be carried out as well as the follow-up of these patients, to observe the evolution of this cortical activation deficit.

It seems however that this test could be a useful instrument to understand more fully the relationship between cortical deficit and the cognitive and early psychiatric symptomatology of HIV infection.

\section{References}

Dew MA, Ragni MV, Nimorwicz P (1990) Infection with human immunodeficiency virus and vulnerability to psychiatric distress. Arch Gen Psychiatry 47, 737-744

Bungener C, Lacour C, Carton S, Lefrere JJ, Widlocher D, Jouvent R (1991) Emotional blunting and sensation seeking in HIV-infected individuals. Eur Psychiatry 6, 99-102

Bobon DP, Lecoq A, von Frenckell R, Lavergne G (1982) Critical flicker fusion frequency. Introduction to the CINP session in Götenborg and methodological recommendations. Pharmacopsychiatr 15, suppl 1, 1-4 